\title{
Pamukta (G. hirsutum L.) Farklı Priming Uygulamalarının Çimlenme ve Fide Gelişim Özellikleri Üzerine Etkisi
}

\author{
Petek TOKLU ${ }^{1 *}$ \\ ${ }^{1}$ Çukurova Üniversitesi, Biyoteknoloji Araştırma ve Uygulama Merkezi, Adana \\ [ORCID ID: http://orcid.org/0000-0002-0975-6272] \\ *Sorumlu yazar: petektoklu@hotmail.com
}

Öz

Ülkemiz için önemli bir ürün olan pamuğun üretim artışında, yüksek verim potansiyeline sahip genetik potansiyeli iyi olan çeşitlerin yetiştirilmesinin yanında, yetiştirme koşullarının optimize edilmesi de önem taşıyan diğer bir faktördür. Bu faktörlerden biri de son yıllarda üzerinde yoğunlaşılan bir konu olan priming (ekim öncesi tohum uygulamaları) giderek önem taşımaktadır. Pamukta farklı priming uygulamalarının tohumun çimlenme özellikleri ile fide gelişimi ve bitki kök ve toprak üstü kuru madde miktarına etkisinin araştıııldığı bu çalışma, Çukurova Üniversitesi, Biyoteknoloji Araştırma ve Uygulama Merkezi laboratuvarları ile araştırma-deneme seralarında 2013 ve 2014 yıllarında yürütülmüştür. Araştırmada, Çukurova koşullarında yaygın olarak yetiştirilen ve bazı bitkisel karakterler yönünden birbirinden farklılık taşıyan SG 125 ve Flash pamuk çeşitlerinin delinte edilmiş tohumları; 1) \%3'lük Potasyumnitrat $\left(\mathrm{KNO}_{3}\right)$, 2) \%10'luk Polietilenglikol (PEG-8000) 3) Mannitol, 4) \%2'lik Potasyum klorür $(\mathrm{KCl})$ ve 5) Saf su priming uygulamalarına tabi tutulmuş, 6) priming uygulamasız tohumlar ise kontrol olarak değerlendirilmiştir.

Elde edilen sonuçlar, hem laboratuvar hem de saksı koşullarında genel olarak Flash çeşidinin çimlenme özelliklerinin SG-125 çeşidine göre daha iyi olduğunu göstermiştir. Bu bağlamda hem petri koşullarında hem de toprak koşullarında saptanan çimlenme hızı ve gücü ile sürme hızı ve gücü değerleri Flash çeşidinde, SG-125 çeşidine kıyasla önemli oranda daha yüksek saptanmışır. Priming uygulamaları içerisinde, özellikle Saf su ve Mannitol uygulamalarını çimlenme ve fide gelişimi yönünden kontrol uygulamaları ve diğer uygulamalara kıyasla avantajlar sağladığı, bu nedenle bu uygulamaların pamuk tarımı yönünden avantaj sağlayabileceği ve bu uygulamalarla ilgili tarla koşullarını da içeren daha detaylı araştırmalar yapılması gerektiği sonucuna varılmıştır.

Anahtar Kelimeler: Pamuk, Priming uygulaması, Çimlenme, Bitkisel özellik

\section{Effects of Different Priming Treatments on Germination and Seedling Growth Properties of Cotton (G. hirsutum L.)}

\begin{abstract}
Cotton is an important fiber crop for Turkey and to increase cotton production it is important to optimize cultivation conditions as well as use of good varieties of genetic potential with high yield potency. Among these factors priming (pre-sowing seed treatments) treatments to the seeds getting importance last decade. This investigation, which is aimed to search the effects of different priming treatments on germination, seedling growth properties, root and shoot growth of cotton was conducted at Çukurova University, Research Laboratory and Greenhauses of Biotechnology Research and Application Center, during 2013-2014 for two years. In this study, delinted seeds of SG-125 and Flash cotton varieties, which were widely grown in Cukurova conditions and differ from each other in terms of some plant characters, used as seed materials. The seeds were treated with priming agents as; 1 ) $3 \%$ Potassium nitrate $\left(\mathrm{KNO}_{3}\right)$, 2) $10 \%$ polyethyleneglycol (PEG-8000) 3) Mannitol, 4) 2\% Potassium chloride (KCl) 5) distilled water and 6) Control (non treated seeds).
\end{abstract}


The results showed that germination properties of Flash variety was superior compared to SG-125 under laboratory and pot conditions. By this context, under the petri and soil conditions germination percentage and seedling emergence percentage were higher in Flash cotton variety than the SG-125. Distilled water and Mannitol treatments to the cotton seeds provided advantages compared to non primed seeds (control) and remaining of the priming agents so, detailed research must be conducted under field conditions to get certain results.

Key Words: Cotton, Priming treatment, Germination, Plant characteristics

\section{Giriş}

Ülkemiz için önemli bir ürün olan pamuğun üretim artışında, yüksek verim potansiyeline sahip genetik potansiyeli iyi olan çeşitlerin yetiştirilmesinin yanında, yetiştirme koşullarının optimize edilmesi de önem taşıyan diğer bir faktördür. Pamukta yüksek verim ve kaliteli üretimin ilk aşaması ekilen tohumların optimum düzeyde çimlenmesi, birim alanda optimum bitki sıklığının sağlanması ve yeterli düzeyde gelişimidir (Fujikura ve ark., 1993; De Villiers ve ark., 1994). Çimlenme ve fide gelişimi birçok bitkide olduğu gibi pamukta da kritik gelişim evresidir. Pamuk bitkisi, özellikle ilk çimlenme ve çıkış döneminde hassas bir bitki olup, Çukurova koşullarında ekim sonrası çıkış problemlerine bağı olarak üreticiler ekimi birkaç kez yenilemek durumunda kalmaktadır. Bu durumda üretim maliyeti artmakta, zaman ve işgücü sarfiyatı yükselmekte ve zaman zaman üreticiler çıkışlarda oluşan problemden dolayı, o sezon pamuk üretiminden bile vazgeçebilmektedir. Bitkisel üretimde, bitkilerde düzenli çıkış, bitki sıklığını, üniform gelişmeyi ve diğer tarımsal uygulamaları etkilemektedir (Cheng ve Bradford, 1999). Bitkilerde çimlenme ve gelişimle ilgili faktörler yıllardır üzerinde çalışılan konular olmuştur. Tohumlara priming uygulaması, ekim öncesi tohum uygulamalarını ifade etmekte olup, çimlenme ve fide gelişimi üzerine etkileri belirlenmiştir (Bradford, 1986; Taylor ve
Harman, 1990). Tohumlara priming uygulaması ile çimlenme öncesi metabolik aktivite sağlanmakta, daha sonra tohumlar ilk nem seviyesine gelinceye kadar kurutulmaktadır (McDonald, 2000). Farklı bitki türlerinde tohumların eşzamanlı olarak çimlenme hızı ve oranını artırmak için çeşitli ön ıslatma ya da priming uygulamaları yapılmıştır (Bradford, 1986). Başlıca priming yöntemleri arasında ozmopriming (tohumların Polietilenglikol gibi ozmotik solusyonlarda bekletilmesi), halopriming (tohumların tuzlu solusyonda bekletilmesi) ve hydropriming (tohumların su içerisinde bekletilmesi) gibi yöntemler sayılmaktadır (Ghasemi-Golezani ve ark., 2008).

Pamukta ve diğer bazı bitkilerde tohuma priming uygulamasının çimlenme ve fide gelişimi üzerinde olumlu etkide bulunarak, optimum bitki sıklığı sağlandığı ve daha yüksek verim elde edildiği birçok araştırmacı tarafından belirtilmiştir (Parera ve Cantliffe, 1994; Harris ve ark., 2005). Priming konusunda yapılan araştırma sonuçları ve üreticilerin tecrübeleri de, tohuma priming uygulamalarının bitkilerin ekimi ile çıkış arasındaki süreyi kısalttığını, daha homojen ve yeknesak bitki çıkışı ve gelişimi sağladığını ve bitkilerin daha erken çiçeklendiğini ortaya koymaktadır (Harris ve ark., 1999). Abandani ve Ramezani (2012), mısırda PEG ve $\mathrm{KNO}_{3}$ uygulamalarının kök kuru ve yaş ağırlığında artış sağladığını ve vigor indeksini artırdığını bildirmişlerdir. Diğer yandan tohuma priming uygulamalarının kuraklık, tuzluluk ve sıcaklık 
stresine dayanıklılı̆ı artırdığı bildirilmiştir. Bagher ve ark., (2012) pamukta tohuma PEG ve $\mathrm{KCl}$ priming uygulamalarının çimlenme ve gelişimi olumlu etkileyen catalyse, peroxidase ve ascorbat peroxidase enzimlerinin oranını artırdığını bildirmişlerdir. Ahmadvand ve ark., (2012) pamuk tohumlarına hydropriming ve $\mathrm{KNO}_{3}$ uygulamalarının çimlenme özellikleri ile tuzluluk stresine dayanıklılığı artırdığını bildirmişler ve en etkili $\mathrm{KNO}_{3}$ konsantrasyonunun $6 \mathrm{~g} \mathrm{KNO}_{3} \mathrm{I}^{-1}$ olduğunu bildirmişlerdir.

Pamukta, çimlenme ve çıkışla ilgili sorunların giderilmesinde farklı priming uygulamalarının etkisine yönelik yürütülen bazı araştırmalarda, farklı priming uygulamalarının çimlenme özellikleri ile verim gibi bitkisel özellikler üzerinde etkili olduğu bildirilmiştir (Hur, 1991; GhasemiGolezani ve ark., 2008). Ozmopriming uygulamalarının soğan (Caseiro ve ark., 2004), karpuz (Demir ve Van de Venter, 1999), biber (Thanos ve ark., 1989; Shakila ve ark., 2005) gibi bazı sebzelerle, buğday (Gri ve Schillinger, 2003) ve şeker pancarı (Gummerson, 1986) gibi tarla bitkilerinde tohumun çimlenme özellikleri yönünden etkili olduğu bildirilmiştir. Tohumların su içerisinde bekletilmesi, aslında geçmiş yıllarda üreticiler tarafından da geleneksel olarak özelikle havlı pamuk tohumlarına yapılan bir uygulama olup, üreticiler genellikle havlı tohumları torbalar içerisinde ya da dökme olarak büyük bir kap ya da havuzda bulunan suyun içerisinde belli bir süre bekletmektedir. Böylece tohum bir miktar su almakta ve ekim öncesi çimlenme faaliyetleri başlamaktadır. Bu sayede, pamuk tohumlarının daha yüksek çimlenme oranı ve daha hızlı çimlenmesi sağlanmakta ve ekim sonrası özellikle pamuk bitkisinde çok sık rastlanan kaymak tabakası bağlama gibi sorunların aşılmasında önem taşımaktadır.

Yukarıda belirtilen bilgiler ışığında bu araştırmanın amacı; pamukta farklı priming uygulamalarının tohumun çimlenme ve sürme özellikleri ile fide gelişimi, bitki kök ve toprak üstü kuru madde miktarına etkisini araştırmaktır.

\section{Materyal ve Metot}

\section{Materyal}

Projeye ilişkin araştırmalar, Çukurova Üniversitesi Biyoteknoloji Araştırma ve Uygulama Merkezi laboratuvarları ile araştırma-deneme seralarında olmak üzere; 2013 yılında laboratuvar araştırmaları, 2014 yılında ise sera çalışmaları yürütülmüştür. Araştırmada materyal olarak; Çukurova koşullarında yaygın olarak yetiştirilen bazı bitkisel karakterler yönünden birbirinden farklılık taşıyan SG 125 ve Flash pamuk çeşitlerinin delinte edilmiş tohumları materyal olarak kullanıımıştır.

Priming uygulamaları ile laboratuvar ve saksı denemeleri

Araştırmada, SG-125 ve Flash pamuk çeşitlerine ait tohumlar hem laboratuvar hem de sera denemelerinde kullanılmak üzere, ekimden önce priming uygulamasına tabi tutulmuştur. Ekim öncesi tohum uygulamaları (priming) olarak 1) \%3'lük Potasyumnitrat $\left.\left(\mathrm{KNO}_{3}\right), 2\right) \quad \%$ 10'luk Polietilenglikol (PEG-8000), 3) Mannitol, 4) $\% 2^{\prime}$ lik Potasyum klorür (KCl) 5) Saf su ve 6) Kontrol (priming uygulamasız tohumlar) incelenmiştir. Her iki pamuk çeşidinin denemeler için yeterli miktarda tohumu hazırlandıktan sonra, yukarıda belirtilen priming solusyonları içerisinde oda sıcaklığında $\left(20{ }^{\circ} \mathrm{C}\right) \quad 12$ saat süreyle bekletilmiştir. Priming uygulaması yapılan 
tohumlar saf su ile yıkandıktan sonra kurutma kağıtlarında nemi alınıp hava ile kurutularak ilk nem seviyesine getirilmiştir. Çimlendirme ve serada yürütülen saksı denemelerinde bu tohumlar kullanılmıştır.

Laboratuvar koşullarında yürütülen çimlendirme testleri, ISTA kurallarına uygun olarak, sıcaklık kontrollü çimlendirme odasında ve 5 farklı priming uygulaması ve kontrol olarak kullanılan tohumlar için, faktöriyel düzende 2 faktörlü tesadüf parselleri deneme desenine göre 4 tekerrürlü olarak yürütülmüştür. Çimlendirme denemeleri petri kaplarında yürütülmüş, her bir petri kabına 25 tohum ekilmiştir. Çimlendirme testleri $25^{\circ} \mathrm{C}$ sıcaklıkta ayarlanmış çimlendirme odalarında karanlık ortamda yürütülmüştür. Araştırmada, her iki çeşitte de, çimlenme hızı (4. gün sayımı), çimlenme gücü (12. gün sayımı), çim uzunluğu ve çim kökü uzunluğu gibi çimlenme özellikleri incelenmiştir.

Sürme testlerine ilişkin araştırmalar iklim odalarında yürütülmüştür. Sürme denemeleri için $10 \times 20 \times 30 \mathrm{~cm}$ ölçülerinde plastik kaplar kullanılmıs ve altık olarak da standart kum ortam kullanılmıştır. Altlık olarak kullanılan kum, sürme denemelerinden önce otoklavda steril edilerek tohumlara enfeksiyon bulaşması engellenmiştir. Her bir kaba 25 tohum ekilmiş ve $25^{\circ} \mathrm{C}$ ortam sıcaklığında 12. gün 1 . sayım, 16. gün 2 . sayım yapılarak sürme hızı ve sürme gücü tespit edilmiştir.

Fide gelişimine ilişkin çalışmalar ise sıcaklık, ışık ve nem kontrollü seralarda yürütülmüş, çimlendirme ortamı olarak $1 / 3$ oranında, toprak, torf ve kum karışımı yetiştirme ortamı olarak kullanılmıştır. Hazırlanan yetiştirme toprakları 16 It'lik saksılara koyulmuştur. Priming uygulaması yapılan tohumlardan her bir saksıya 5 adet tohum ekilmiştir. Saksı denemeleri 4 tekerürlü faktöriyel düzende, 2 faktörlü tesadüf parselleri deneme desenine göre yürütülmüştür.

Araştırmanın laboratuvar koşullarında incelenen bitkisel karakterler ile yöntemleri aşağıda verilmiştir.

Çimlenme hızı ve gücü (\%): Sıcaklık kontrollü çimlendirme dolabında $\left(25^{\circ} \mathrm{C}\right)$, petri kaplarındaki tohumlarda 4 . gün ve 12 . günlerde çimlenen tohumlar sayılarak farklı priming uygulaması yapılmış tohumlar için çimlenme hızı ve çimlenme gücü belirlenmiştir.

Çim uzunluğu $(\mathrm{cm})$ : Petri kaplarında çimlenmesini tamamlayan tohumlarda 12. gün sonunda, her petriden rastgele seçilen 5 bitkide çim uzunlukları ölçülerek $\mathrm{cm}$ olarak belirlenmiştir.

Çim kökü uzunluğu $(\mathrm{cm})$ : Petri kaplarında çimlenmesini tamamlayan tohumlarda 12. gün sonunda her petriden rastgele seçilen 5 bitkide çim kökleri dijital kumpas ile ölçülerek, ortalama çim kökü uzunlukları cm olarak belirlenmiştir.

Sürme hızı ve gücü (\%) : Sürme testleri için, $25^{\circ} \mathrm{C}$ ortam sıcaklığında, $15 \times 20 \times 30 \mathrm{~cm}$ ölçülerinde plastik kaplara steril kum doldurulmuş ve bunlar içerisine ekilen 25 tohumda ekimden 12 ve 16 gün sonra sayım yapılarak, sırasıyla sürme hızı ve gücü belirlenmiştir.

Sürgün ve kök kuru ağırlıkları (g bitki ${ }^{-1}$ ) : Sürme denemelerinden elde edilen bitkilerde, her sürme kabından 16. günde alınan 5 bitki kök boğazından kesilerek, sürgünler ve kökler ayrı ayrı $80^{\circ} \mathrm{C}$ 'de 12 saat kurutularak, her bir priming uygulaması için 
ortalama sürgün kuru ağırlı̆ı ve kök kuru ağırlığı saptanmıştır.

Araştırmanın sera çalışmalarında incelenen bitkisel karakterler ile yöntemleri aşağıda verilmiştir.

Bitki boyu $(\mathrm{cm})$ : Sera koşullarında, her saksıda yetiştirilen 5 adet bitkide, taraklanma başlangıcı döneminde toprağın hemen yüzeyinden en uçtaki sürgün ucuna kadar olan mesafe ölçülerek saptanmıştır.

Kök uzunluğu $(\mathrm{cm})$ : Sera koşullarında, her saksıda yetiştirilen 5 adet bitkide, taraklanma başlangıcı döneminde topraktan çıkarılarak yıkanmış ve kök boğazından kök ucuna kadar olan mesafe ölçülerek saptanmıştır.

Sürgün ve kök kuru ağırlıkları $\left(g\right.$ bitki $\left.^{-1}\right)$ : Serada saksılarda yetiştirilen 5 adet bitki, taraklanma başlangıcı döneminde saksılardan çıkarılarak kökler su ile dikkatlice yıkanmış ve kök boğazından kesilerek sürgünler ve kökler ayrı ayrı olmak üzere, kurutma dolabında $80{ }^{\circ} \mathrm{C}^{\prime}$ de 12 saat kurutularak, her bir priming uygulaması için ortalama kök ve sürgün kuru ağırlıkları tespit edilmiştir.

Toplam kuru madde miktarı ( $g$ bitki ${ }^{-1}$ ): Serada saksılarda yetiştirilen ve toprak üstü ve kök kuru madde miktarı saptanan bitkilerin kök ve toprak üstü kuru madde miktarları toplanarak saptanmıştır.

Fide büyüme hızı ( $m m$ gün $\left.{ }^{-1}\right)$ : Kontrollü seralarda, saksılarda yetiştirilen bitkilerde, çıkıstan itibaren haftada bir olmak üzere 2 ay süre ile bitki boyları ölçülerek günlük ortalama büyüme oranı belirlenmiştir.

\section{Araştırma Bulguları ve Tartışma}

\section{Laboratuvar denemeleri}

Araştırma kapsamında, laboratuvar koşullarında yürütülen çimlendirme testlerinden elde edilen çimlenme hızı (\%), çimlenme gücü $(\%)$, çim uzunluğu $(\mathrm{cm})$, çim kökü uzunluğu $(\mathrm{cm})$ ile sürme denemelerinden elde edilen sürme hızı (\%), sürme gücü (\%), sürgün kuru ağırlığı (g bitki ${ }^{-1}$ ) ve kök kuru ağırlığına ( $\mathrm{g}$ bitki ${ }^{-1}$ ) ilişkin varyans analiz sonuçları Çizelge $1^{\prime}$ de, saksı denemelerinde saptanan bitki boyu $(\mathrm{cm})$, kök uzunluğu $(\mathrm{cm})$, sürgün kuru ağırlığı (g bitki $^{-1}$ ) kök kuru ağırlığı (g bitki ${ }^{-1}$ ), toplam kuru madde miktarı ( $\mathrm{g} \mathrm{bitki}^{-1}$ ) ve fide büyüme hızı (mm gün $\left.{ }^{-1}\right)^{\prime} n a$ ilişkin varyans analiz sonuçları Çizelge 2'de, priming uygulamaları ve çeşitlere ilişkin ortalama veriler ise Çizelge 3 ve Çizelge 4 'te verilmiştir. 
Çizelge 1. Pamuk tohumuna farklı priming uygulamalarının laboratuvar koşullarında bazı çimlenme özelliklerine etkisine ilişkin varyans analiz sonuçları Table 1. Results of variance analysis on the effect of different priming applications on cotton for some germination properties in laboratory conditions

\begin{tabular}{|c|c|c|c|c|c|c|c|c|}
\hline $\begin{array}{l}\text { Varyasyon kaynağı } \\
\text { Source of variation }\end{array}$ & $\begin{array}{c}\text { Çimlenme hızı } \\
\text { Germination } \\
\text { rate } \\
(\%)\end{array}$ & $\begin{array}{l}\text { Çimlenme } \\
\text { gücü } \\
\text { Germination } \\
\text { vigour } \\
(\%) \\
\end{array}$ & $\begin{array}{l}\text { Çim uzunluğu } \\
\text { Shoot length } \\
\text { (cm) }\end{array}$ & $\begin{array}{l}\text { Çim kökü } \\
\text { uzunluğu } \\
\text { Seedling root } \\
\text { length } \\
\text { (cm) }\end{array}$ & $\begin{array}{l}\text { Sürme hızı } \\
\text { Seedling } \\
\text { germination } \\
\text { rate } \\
(\%) \\
\end{array}$ & $\begin{array}{l}\text { Sürme Gücü } \\
\text { Seedling } \\
\text { emergence } \\
(\%)\end{array}$ & $\begin{array}{l}\text { Sürgün kuru } \\
\text { ağırlığı } \\
\text { Shoot dry } \\
\text { weight } \\
\text { (g) }\end{array}$ & $\begin{array}{l}\text { Kök kuru } \\
\text { ağırlığı } \\
\text { Root dry } \\
\text { weight } \\
\text { (g) }\end{array}$ \\
\hline $\begin{array}{l}\text { Çeşit } \\
\text { Variety }\end{array}$ & $10561.3^{* *}$ & $8112.0 * *$ & 0.022 & 1.394 & $2080.3^{* *}$ & $1925.3^{* *}$ & $0.073 * *$ & 0.0014 \\
\hline Priming & 223.2 & 338.1 & $1.83^{* *}$ & 0.416 & $189.9 * *$ & $175.7^{* *}$ & $0.0074 * *$ & $0.013^{* *}$ \\
\hline $\begin{array}{l}\text { ÇeşitxPriming } \\
\text { VarietyxPriming }\end{array}$ & 215.7 & 304.0 & 0.092 & $2.90 * *$ & 68.3 & 69.3 & $0.0046^{*}$ & 0.0017 \\
\hline
\end{tabular}

Uygulamalar arasındaki fark, ${ }^{*}: 0.05$ olasılık düzeyinde, ${ }^{* *}: 0.01$ olasılık düzeyinde istatistiki olarak önemli

The difference between the applications is statistically significant at the *: 0.05 probability level, **: 0.01 probability level

Çizelge 2. Pamuk tohumuna farklı priming uygulamalarının saksı koşullarında bazı bitkisel özelliklerine etkisine ilişkin varyans analiz sonuçları Table 2. Results of variance analysis on the effect of different priming applications on cotton for some plant characteristics in pot conditions

\begin{tabular}{|c|c|c|c|c|c|c|}
\hline $\begin{array}{l}\text { Varyasyon kaynağı } \\
\text { Source of variation }\end{array}$ & $\begin{array}{l}\text { Bitki boyu } \\
\text { Plant height } \\
\text { (cm) }\end{array}$ & $\begin{array}{l}\text { Kök uzunluğu } \\
\text { Root length } \\
\text { (cm) }\end{array}$ & $\begin{array}{l}\text { Sürgün kuru ağırlığı } \\
\text { Shoot dry weight } \\
\left(\mathrm{g} \text { bitki }{ }^{-1}\right)\end{array}$ & $\begin{array}{l}\text { Kök kuru ağırlığı } \\
\text { Root dry weight } \\
\quad\left(\mathrm{g} \mathrm{bitki}^{-1}\right)\end{array}$ & $\begin{array}{c}\text { Toplam kuru madde } \\
\text { miktarı } \\
\text { Total dry weight } \\
\left(\mathrm{g} \mathrm{bitki}{ }^{-1}\right)\end{array}$ & $\begin{array}{l}\text { Fide büyüme hızı } \\
\text { Seedling growth rate } \\
\left(\mathrm{mm}_{\text {gün }}{ }^{-1}\right)\end{array}$ \\
\hline $\begin{array}{l}\text { Çeşit } \\
\text { Variety }\end{array}$ & 11.45 & $53.34 *$ & $7.45^{* *}$ & $0.65^{* *}$ & $12.53 * *$ & $11.87^{* *}$ \\
\hline Priming & $93.58^{* *}$ & 12.44 & $2.44 * *$ & $0.207^{* *}$ & $4.33 * *$ & $6.53 * *$ \\
\hline $\begin{array}{l}\text { ÇeşitxPriming } \\
\text { VarietyxPriming }\end{array}$ & 25.72 & 17.80 & $2.81^{* *}$ & 0.110 & $3.99 * *$ & 1.38 \\
\hline
\end{tabular}

Uygulamalar arasındaki fark, *: 0.05 olasılık düzeyinde, ${ }^{* *}: 0.01$ olasilık düzeyinde istatistiki olarak önemli

The difference between the applications is statistically significant at the *: 0.05 probability level, **: 0.01 probability level 
Çizelge 3. Pamukta farklı priming uygulamalarının laboratuvar koşullarında çimlenme hızı, çimlenme gücü, çim uzunluğu ve çim kökü uzunluğu üzerine etkisi Table 3. Effect of different priming treatments seed on germination rate, germination vigour, seedling length and seedling root length under laboratory conditions

\begin{tabular}{|c|c|c|c|c|c|c|c|c|c|c|c|c|}
\hline \multirow{2}{*}{$\begin{array}{l}\text { Priming } \\
\text { uygulaması } \\
\text { Priming } \\
\text { treatment }\end{array}$} & \multicolumn{3}{|c|}{$\begin{array}{c}\text { Çimlenme hızı } \\
\text { Germination rate } \\
(\%)\end{array}$} & \multicolumn{3}{|c|}{$\begin{array}{c}\text { Çimlenme gücü } \\
\text { Germination vigour } \\
(\%)\end{array}$} & \multicolumn{3}{|c|}{$\begin{array}{l}\text { Çim uzunluğu } \\
\text { Seedling length } \\
\text { (cm) }\end{array}$} & \multicolumn{3}{|c|}{$\begin{array}{l}\text { Çim kökü uzunluğu } \\
\text { Seedling root length } \\
(\mathrm{cm})\end{array}$} \\
\hline & SG-125 & Flash & Ortalama & SG-125 & Flash & Ortalama & SG-125 & Flash & Ortalama & SG-125 & Flash & Ortalama \\
\hline $\mathrm{KNO}_{3}$ & 67.2 & 97.2 & 82.2 & 73.0 & 92.0 & 82.5 & 1.30 & 1.45 & $1.37 b^{* *}$ & $1.66 \mathrm{~d}$ & $2.98 \mathrm{abc}$ & 2.32 \\
\hline PEG & 77.2 & 99.2 & 88.2 & 88.0 & 99.0 & 93.5 & 1.69 & 1.78 & $1.74 \mathrm{~b}$ & $2.72 \mathrm{bcd}$ & $2.96 \mathrm{abc}$ & 2.84 \\
\hline Mannitol & 80.0 & 100.0 & 90.0 & 89.0 & 100.0 & 94.5 & 2.54 & 2.34 & $2.44 \mathrm{a}$ & $2.47 \mathrm{bcd}$ & $2.38 \mathrm{bcd}$ & 2.42 \\
\hline $\mathrm{KCL}$ & 65.2 & 99.2 & 82.2 & 70.0 & 97.0 & 83.5 & 1.93 & 1.68 & $1.80 \mathrm{~b}$ & $3.05 a b c$ & $2.70 \mathrm{bcd}$ & 2.87 \\
\hline Saf Su & 72.0 & 96.0 & 84.0 & 78.0 & 98.0 & 88.0 & 2.54 & 2.73 & $2.63 a$ & $3.21 \mathrm{ab}$ & $2.01 \mathrm{~cd}$ & 2.61 \\
\hline Kontrol & 51.2 & 99.2 & 75.2 & 69.0 & 98.0 & 83.5 & 1.62 & 1.90 & $1.76 \mathrm{~b}$ & $1.69 \mathrm{~d}$ & $3.84 \mathrm{a}$ & 2.76 \\
\hline Ortalama & $68.8 \mathrm{~B}^{* *}$ & $98.5 \mathrm{~A}$ & & $77.8 \mathrm{~B}^{* *}$ & $97.3 \mathrm{~A}$ & & 1.93 & 1.98 & & 2.47 & 2.81 & \\
\hline
\end{tabular}

Aynı harf grubuna giren ortalamalar LSD testine göre *: \%5 önem seviyesine, **: \%1 önem seviyesine göre farksızdır.

The averages in the same letter group is no difference according to LSD test ${ }^{*}: 5 \%$ significance level, **: $1 \%$ significance level.

Çizelge 4. Pamukta farklı priming uygulamalarının laboratuvar koşullarında sürme hızı, sürme gücü, sürgün kuru ağırlığı ve kök kuru ağırlığı üzerine etkisi

Table 4. Effect of different priming treatments on seedling emergence rate, seedling emergence vigour, seedling dry weight and root dry weight under laboratory conditions

\begin{tabular}{|c|c|c|c|c|c|c|c|c|c|c|c|c|}
\hline \multirow{2}{*}{$\begin{array}{l}\text { Priming } \\
\text { uygulaması } \\
\text { Priming } \\
\text { treatment }\end{array}$} & \multicolumn{3}{|c|}{$\begin{array}{c}\text { Sürme hızı } \\
\text { Seedling emergence rate } \\
(\%)\end{array}$} & \multicolumn{3}{|c|}{$\begin{array}{c}\text { Sürme gücü } \\
\text { Seedling emergence vigour } \\
(\%)\end{array}$} & \multicolumn{3}{|c|}{$\begin{array}{l}\text { Sürgün kuru ağırlığı } \\
\text { Seedling dry weight } \\
\left.\text { (g bitki }{ }^{-1}\right)\end{array}$} & \multicolumn{3}{|c|}{$\begin{array}{l}\text { Kök kuru ağırlığı } \\
\text { Root dry weight } \\
\left.\text { (g bitki }{ }^{-1}\right)\end{array}$} \\
\hline & SG-125 & Flash & Ortalama & SG-125 & Flash & Ortalama & SG-125 & Flash & Ortalama & SG-125 & Flash & Ortalama \\
\hline $\mathrm{KNO}_{3}$ & 74.0 & 91.0 & $82.5 c^{* *}$ & 74.0 & 93.0 & $83.5 b^{* *}$ & 0.466 bc* & $0.360 \mathrm{f}$ & $0.413 b c^{* *}$ & 0.155 & 0.160 & $0.157 b^{* *}$ \\
\hline PEG & 85.0 & 97.0 & $91.0 \mathrm{ab}$ & 88.0 & 98.0 & $93.0 \mathrm{a}$ & $0.478 \mathrm{~b}$ & $0.433 \mathrm{~b}-\mathrm{e}$ & $0.455 \mathrm{ab}$ & 0.155 & 0.214 & $0.184 \mathrm{~b}$ \\
\hline Mannitol & 92.0 & 100.0 & $96.0 \mathrm{a}$ & 92.0 & 100.0 & $96.0 \mathrm{a}$ & $0.465 \mathrm{bc}$ & 0.397 def & 0.431 bc & 0.167 & 0.166 & $0.166 \mathrm{~b}$ \\
\hline $\mathrm{KCL}$ & 77.0 & 100.0 & 88.5 bc & 79.0 & 100.0 & $89.5 \mathrm{ab}$ & $0.449 \mathrm{bcd}$ & $0.410 \mathrm{c}-\mathrm{f}$ & 0.429 bc & 0.235 & 0.229 & $0.232 \mathrm{a}$ \\
\hline Saf Su & 88.0 & 99.2 & $93.5 \mathrm{ab}$ & 88.0 & 99.2 & $93.5 \mathrm{a}$ & $0.567 \mathrm{a}$ & $0.403 c-f$ & $0.485 \mathrm{a}$ & 0.146 & 0.180 & $0.163 b$ \\
\hline Kontrol & 90.0 & 98.0 & $94.0 \mathrm{ab}$ & 92.0 & 99.0 & $95.5 \mathrm{a}$ & 0.424 b-e & 0.375 ef & $0.399 \mathrm{c}$ & 0.120 & 0.096 & $0.108 \mathrm{c}$ \\
\hline Ortalama & $84.3 \mathrm{~B}^{* *}$ & $97.5 \mathrm{~A}$ & & $85.5 \mathrm{~B}^{* *}$ & $98.2 \mathrm{~A}$ & & $0.475 A^{* *}$ & $0.396 \mathrm{~B}$ & & 0.163 & 0.174 & \\
\hline
\end{tabular}

Aynı harf grubuna giren ortalamalar LSD testine göre *: \%5 önem seviyesine, **: \%1 önem seviyesine göre farksızdır.

The averages in the same letter group is no difference according to LSD test *: $5 \%$ significance level, **: $1 \%$ significance level. 
Çizelge 3'ün incelenmesinden görüleceği gibi, Flash çeşidinde saptanan çimlenme hızı (sırasıyla \%98.5), SG-125 pamuk çeşidinde saptanan çimlenme hızından \%68.8) daha yüksek bulunmuştur. Priming uygulamalarına bağlı olarak saptanan çimlenme hızı değerleri genel olarak mannitol ve PEG uygulamalarında diğer uygulamalardan daha yüksek saptanmıştır. En yüksek çimlenme hızı değeri mannitol uygulamasından (\%90), elde edilirken en düşük çimlenme hızı ise kontrol uygulamasından (\%75.2) elde edilmiştir.

Flash pamuk çeşidinde saptanan çimlenme gücü değerleri (\% 97.3), SG-125 pamuk çeşidinde saptanan çimlenme gücü değerlerinden (\% 77.8) daha yüksek bulunmuştur. íki çeşidin ortalama verilerine göre priming uygulamalarına bağlı olarak çimlenme gücü değerleri yönünden mannitol uygulamasının (\%94.5), çimlenme gücünü diğer uygulamalara kıyasla artırdığı Çizelge 3'den görülmektedir.

Çim uzunluğu yönünden çeşitler arasında önemli bir fark saptanmazken, iki çeşidin ortalama verilerine göre en yüksek çim uzunluğu değeri 2.63 ve $2.44 \mathrm{~cm}$ ile sırasıyla saf su ve mannitol uygulamalarında saptanmıştır. SG-125 ve Flash pamuk çeşitlerinin her ikisinde de en düşük çim uzunluğu $\mathrm{KNO}_{3}$ priming uygulamasından elde edilmiştir. iki çeşidin ortalama verilerine göre en düşük çim uzunluğu $1.37 \mathrm{~cm}$ ile $\mathrm{KNO}_{3}$ uygulamasından saptanmıştır.

SG-125 ve Flash pamuk çeşitlerinin çim kökü uzunluğu yönünden priming uygulamalarına tepkilerinin farklı olduğu saptanmıştır. En yüksek çim kökü uzunluğu Flash çeşidinde kontrol uygulamasında (3.84 $\mathrm{cm})$ saptanırken, en düşük çim kökü uzunluğu SG-125 çeşidinde $\mathrm{KNO}_{3}$ ve Kontrol uygulamalarında (sırasıyla 1.66 ve $1.69 \mathrm{~cm}$ ) saptanmıştır.
Araştırma kapsamında sürme denemelerinden elde edilen sürme hızı yönünden (Çizelge 4) priming uygulamalarına bağlı olarak çeşitlerin genel ortalamaları arasında saptanan farkın istatistiki olarak önemli olduğu, Flash çeşidinde saptanan sürme hızı değerinin (\%97.5), SG-125 çeşidinden (\%84.3) önemli düzeyde daha yüksek olduğu saptanmıştır. Sürme hızı yönünden saptanan çeşit $x$ priming interaksiyonu istatistiki olarak önemli olmamakla birlikte, en yüksek sürme hızı değeri Flash çeşidinde Mannitol ve $\mathrm{KCl}$ uygulamalarından, en düşük sürme hızı değerleri ise SG-125 çeşidinde $\mathrm{KNO}_{3}$ uygulamasından (\%74) elde edilmiştir. İki pamuk çeşidinin ortalama verilerine göre en düşük sürme hızı değeri $\mathrm{KNO}_{3}$ uygulamasından elde edilirken (\%82.5), en yüksek sürme hızı değerinin $\% 96.0$ ile Mannitol uygulamasından elde edildiği görülmektedir .

Sürme gücü yönünden Priming uygulamalarına bağlı olarak çeşitlerin genel ortalamaları arasında saptanan farkın istatistiki olarak önemli olduğu, Flash çeşidinde saptanan sürme gücü değerinin (\%98.2), SG-125 çeşidinden (\%85.5) önemli düzeyde daha yüksek olduğu saptanmıştır. íki pamuk çeşidinin ortalama verilerine göre priming uygulamaları arasında saptanan farkın istatistiki düzeyde önemli olduğu, en düşük sürme gücü değeri $\mathrm{KNO}_{3}$ uygulamasından elde edilirken (\% 83.5), en yüksek sürme hızı değerinin $\% 96.0$ ile Mannitol uygulamasından elde edildiği görülmektedir (Çizelge 4).

Pamuk tohumlarında farklı priming uygulamalarının sürgün kuru ağırlığı üzerine etkisi incelendiğinde (Çizelge 4) çeşit $x$ priming interaksiyonunun önemli olduğu, en yüksek sürgün kuru ağırlığı SG-125 çeşidinde saf su uygulamasından elde edilirken (0.567 
g bitki ${ }^{-1}$ ) en düşük kontrol uygulamasından

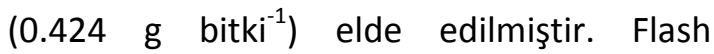
çeşidinde en yüksek PEG uygulamasından $\left(0.433 \mathrm{~g} \mathrm{bitki}{ }^{-1}\right)$, en düşük ise $\mathrm{KNO}_{3}$ uygulamasından $\left(0.360 \mathrm{~g}\right.$ bitki $\left.{ }^{-1}\right)$ elde edilmiştir. îki pamuk çeşidinin ortalama verilerine göre priming uygulamalarına bağı olarak sürgün kuru ağırlıkları arasında oluşan fark istatistiki düzeyde önemli bulunmuş, en yüksek sürgün kuru ağırlığı $0.485 \mathrm{~g}$ ile saf su uygulamasından elde edilirken, en düşük sürgün kuru ağırlığı $0.399 \mathrm{~g}$ ile kontrol uygulamasından elde edilmiştir. SG-125 çeşidinde saptanan sürgün kuru ağırlığının (0.475 g), Flash çeşidinden (0.396 g) daha yüksek olduğu saptanmıştır. SG-125 pamuk çeşidinde en yüksek sürgün kuru ağırlığı PEG uygulamasından elde edilirken, Flash çeşidinde ise Kontrol ve Mannitol uygulamasından saptanmıştır.

Pamuk tohumlarında farklı priming uygulamalarının kök kuru ağırlığı üzerine etkisi incelendiğinde (Çizelge 4) çeşitlerin ortalamalarına göre priming uygulamalarına bağlı olarak saptanan kök kuru ağırlıkları arasındaki fark önemli bulunmuş olup, en yüksek kök kuru ağırlığı $\mathrm{KCl}$ uygulamasından (0.232 $\mathrm{g} \mathrm{bitki}{ }^{-1}$ ) saptanırken, en düşük kontrol uygulamasından (0.108 g bitki $\left.{ }^{-1}\right)$ saptanmıştır.

Çizelge 3 ve 4 'deki verilere göre, çimlenme parametreleri yönünden pamuk çeşitleri arasında genotipik bir farklııı olduğu, Flash pamuk çeşidinin genel olarak çimlenme ve sürme oranı yönünden SG-125 pamuk çeşidinden daha iyi durumda olduğu saptanmıştır. Pamukta çimlenme faktörleri üzerinde çevre koşullarının önemi yanında genetik potansiyelin de önemli olduğu belirtilmiştir (Bradow ve Bauer, 2010). Pamukta, tohumun çimlenme parametreleri üzerinde, farklı genetik kaynaklardan gelen genotip etkisinin önemli olduğu belirtilmiştir
(Buxton ve Sprenger, 1975). Araştırmamızda yer alan pamuk çeşitlerinin çimlenme özellikleri yönünden farklılık göstermesi bu bağlamda açıklanabilir. Araştırma sonuçlarına göre, pamuk tohumuna farklı priming uygulamalarının, çimlenme parametreleri üzerinde etkili olduğu, çimlenme hızı ve çimlenme gücü yönünden mannitol ve $P E G$, çim uzunluğu yönünden saf su ve mannitol, çim kökü uzunluğu yönünden $\mathrm{KCl}$ ve PEG uygulamalarının artış sağladığı, sürme parametrelerinden sürme hızı ve gücü yönünden mannitol uygulamasının, sürgün kuru ağırlığı yönünden saf su, kök kuru ağırlığı yönünden $\mathrm{KCl}$ uygulamalarının diğer priming uygulamaları ve kontrole kıyasla artış sağlaması dikkati çekmektedir. Konu ile ilgili yürütülen kimi araştırmalarda, pamuk tohumuna priming uygulamasının kontrole kıyasla kuraklık stresine dayanıklılığı artırdığı (Murungu ve ark., 2005), pamuk tohumlarına hydropriming ve $\mathrm{KNO} 3$ priming uygulamalarının tuz stresine dayanıklılığ artırdığı, tuz stresi altında kontrol uygulamasına kıyasla çimlenme, fide gelişimi, kök ve sürgün gelişimini artırdığını (Nazir ve ark., 2014), mannitol priming uygulamasının yeni hasat edilen ve depolanmış tohumlarda çimlenme hızı ve vigor indeksini artırdığı (Toselli ve Casenave, 2014), pamuk tohumlarının -0.5 MPa ozmotik basınçta mannitol solüsyonunda $16{ }^{\circ} \mathrm{C}^{\prime}$ de 6 ya da 12 saat bekletilmesinin olumsuz koşullarda ve marjinal alanlarda daha iyi çimlenmeye neden olduğu (Papastylionou ve Karamanos, 2012) bildirilmiş olup, elde edilen bu sonuçlar bizim araştırmamızdan elde ettiğimiz sonuçlarla benzerlik göstermektedir. 


\section{Saksı denemeleri}

Farklı priming uygulamalarına bağlı olarak sera ortamında saksı koşullarında bitki boyu $(\mathrm{cm})$, kök uzunluğu $(\mathrm{cm})$ ve sürgün kuru ağırlığına (g bitki ${ }^{-1}$ ) ilişkin ortalama veriler aşağıda Çizelge 5 'te verilmiştir.

Çizelge 5. Farklı priming uygulamalarının saksı koşullarında pamukta bitki boyu, kök uzunluğu ve sürgün kuru ağırlı̆̆ı üzerine etkisi

Table 5. Effect of different priming treatments on plant height, root length and shoot dry weight in cotton under pot conditions

\begin{tabular}{|c|c|c|c|c|c|c|c|c|c|}
\hline \multirow[t]{2}{*}{$\begin{array}{l}\text { Priming } \\
\text { uygulaması } \\
\text { Priming } \\
\text { treatment }\end{array}$} & \multicolumn{3}{|c|}{$\begin{array}{l}\text { Bitki boyu } \\
\text { Plant height } \\
(\mathrm{cm})\end{array}$} & \multicolumn{3}{|c|}{$\begin{array}{l}\text { Kök uzunluğu } \\
\text { Root length } \\
\text { (cm) }\end{array}$} & \multicolumn{3}{|c|}{ 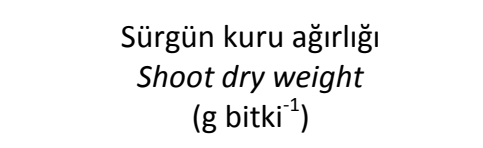 } \\
\hline & SG-125 & Flash & Ort. & SG-125 & Flash & Ort. & SG-125 & Flash & Ort. \\
\hline $\mathrm{KNO}_{3}$ & 51.2 & 45.7 & $48.4 a^{* *}$ & 39.3 & 38.2 & 38.8 & $11.49 a b^{* *}$ & 10.32 b-e & $10.90 a^{* *}$ \\
\hline PEG & 43.7 & 43.8 & $43.7 \mathrm{abc}$ & 38.5 & 40.5 & 39.5 & 9.29 e & $9.92 \mathrm{cde}$ & $9.60 \mathrm{c}$ \\
\hline Mannitol & 48.9 & 45.7 & $47.3 \mathrm{ab}$ & 34.3 & 37.4 & 35.9 & $9.36 \mathrm{e}$ & $10.71 \mathrm{a}-\mathrm{d}$ & $10.04 \mathrm{bc}$ \\
\hline $\mathrm{KCL}$ & 47.8 & 44.7 & $46.2 \mathrm{ab}$ & 38.0 & 36.9 & 37.5 & $11.09 \mathrm{abc}$ & $11.22 \mathrm{ab}$ & $11.15 \mathrm{a}$ \\
\hline Saf Su & 40.9 & 44.7 & $42.8 \mathrm{bc}$ & 34.7 & 41.5 & 38.1 & $9.87 \mathrm{de}$ & $11.78 \mathrm{a}$ & $10.83 \mathrm{ab}$ \\
\hline Kontrol & 38.1 & 40.2 & $39.1 \mathrm{c}$ & 36.1 & 39.0 & 37.6 & $9.85 \mathrm{de}$ & $11.72 \mathrm{a}$ & $10.79 a b$ \\
\hline Ortalama & 45.1 & 44.1 & & $36.8 B^{*}$ & $38.9 A$ & & $10.16 B^{* *}$ & $10.95 A$ & \\
\hline
\end{tabular}

Aynı harf grubuna giren ortalamalar LSD testine göre *: \%5 önem seviyesine, ${ }^{* *}$ : \%1 önem seviyesine göre farksızdır.

The averages in the same letter group is no difference according to LSD test *: 5\% significance level, **: $1 \%$ significance level.

Çizelge 5'den, SG-125 ve Flash pamuk çeşitlerinin her ikisinde de en düşük bitki boyu değerleri kontrol uygulamasından elde edilirken (sırasıyla 38.1 ve $40.2 \mathrm{~cm}$ ), en yüksek bitki boyu SG-125 çeşidinde $\mathrm{KNO}_{3}$ uygulamasından $(51.2 \mathrm{~cm})$, Flash çeşidinde ise $\mathrm{KNO}_{3}$ ve Mannitol uygulamalarından $(45.7 \mathrm{~cm})$ elde edilmiştir. İki çeşidin ortalama verileri arasındaki fark istatistiki olarak önemli bulunmuş, ortalama verilere göre en düşük bitki boyu değeri herhangi bir uygulama yapılmayan kontrol bitkilerinde saptanırken $(39.1 \mathrm{~cm})$, en yüksek bitki boyu $48.4 \mathrm{~cm}$ ile $\mathrm{KNO}_{3}$ uygulamasından ikinci sırada ise $47.3 \mathrm{~cm}$ ile mannitol uygulamasından elde edilmiştir.

Farklı priming uygulamalarına bağlı olarak en düşük kök uzunluğu $34.3 \mathrm{~cm}$ ile PEG uygulamasından, en yüksek ise $39.3 \mathrm{~cm}$ ile $\mathrm{KNO}_{3}$ uygulamasından elde edilmiştir
(Çizelge 5). Flash pamuk çeşidinde ise en düşük kök uzunluğu $36.9 \mathrm{~cm}$ ile Mannitol uygulamasından, en yüksek ise $41.5 \mathrm{~cm}$ ile saf su uygulamasından saptanmıştır. íki çeşidin ortalama verilerine göre priming uygulamalarına bağlı olarak saptanan kök uzunlukları arasındaki fark istatistiki düzeyde önemli bulunmamakla birlikte en düşük kök uzunluğu $35.9 \mathrm{~cm}$ ile PEG uygulamasından, en yüksek ise $39.5 \mathrm{~cm}$ ile $\mathrm{KCl}$ uygulamasından elde edilmiştir. Ortalama verilere göre Flash pamuk çeşidinde saptanan kök uzunluğu $(38.9 \mathrm{~cm})$, SG-125 pamuk çeşidinde saptanan kök uzunluğundan $(36.8 \mathrm{~cm})$ daha yüksek bulunmuştur.

Sürgün kuru ağırlığı yönünden pamuk çeşitleri ve priming uygulamaları arasındaki fark ve çeşit $x$ priming interaksiyonunun istatistiki düzeyde önemli olduğu 
saptanmıştır (Çizelge 5). SG-125 pamuk çeşidinde en düşük sürgün kuru ağırlığı 9.29 $\mathrm{g}$ bitki $^{-1}$ ile $\mathrm{KCl}$ ve $9.36 \mathrm{~g}_{\text {bitki }}{ }^{-1}$ ile mannitol uygulamasından, en yüksek ise $11.49 \mathrm{~g} \mathrm{bitki}^{-1}$ ile $\mathrm{KNO}_{3}$ uygulamasından elde edilmiştir. Flash pamuk çeşidinde ise en düşük sürgün kuru ağırlığı $9.92 \mathrm{~g}$ bitki ${ }^{-1}$ ile $\mathrm{KCl}$ uygulamasından, en yüksek ise $11.78 \mathrm{~g} \mathrm{bitki}^{-1}$ ile saf su uygulamasından saptanmıştır.

Farklı priming uygulamalarına bağlı olarak sera ortamında saksı koşullarında bitki boyu $(\mathrm{cm})$, kök uzunluğu $(\mathrm{cm})$ ve sürgün kuru ağırlığına ( $\left(\mathrm{g}\right.$ bitki ${ }^{-1}$ ) ilişkin ortalama veriler aşağıda Çizelge 6 'da verilmiştir.

Çizelge 6'nın incelenmesinden, oluşan farklar istatistiki düzeyde önemli olmamakla birlikte SG-125 pamuk çeşidinde en düşük kök kuru ağırlığı $1.22 \mathrm{~g} \mathrm{bitki}^{-1}$ ile PEG uygulamasından, en yüksek ise $1.82 \mathrm{~g} \mathrm{bitki}^{-1}$ ile $\mathrm{KNO}_{3}$ uygulamasından elde edilmiştir. Flash pamuk çeşidinde ise en düşük kök kuru ağırlığı $1.52 \mathrm{~g} \mathrm{bitki}^{-1}$ ile $\mathrm{KCl}$ uygulamasından, en yüksek ise $2.06 \mathrm{~g} \mathrm{bitki}^{-1}$ ile Kontrol uygulamasından saptanmıştır. iki çeşidin ortalama verilerine göre priming uygulamalarına bağı olarak saptanan kök kuru ağırlıkları arasındaki fark istatistiki düzeyde önemli bulunmuş ve en düşük kök kuru ağırlığı $1.42 \mathrm{~g}$ bitki $^{-1}$ ile PEG uygulamasından, en yüksek ise $1.81 \mathrm{~g} \mathrm{bitki}^{-1}$ ile Kontrol uygulamasından elde edilmiştir. Ortalama verilere göre Flash pamuk çeşidinde saptanan kök kuru ağırlığı (1.73 g bitki $^{-1}$ ), SG-125 pamuk çeşidinde saptanan kök kuru ağırlığından (1.50 g bitki ${ }^{-1}$ ) daha yüksek bulunmuştur.

Çizelge 6. Farklı priming uygulamalarının saksı koşullarında pamukta kök kuru ağırlığı, toplam kuru madde miktarı ve fide büyüme hızı üzerine etkisi

Table 6. Effect of different priming treatments on root dry weight, total dry matter and seedling growth rate in pot conditions of cotton

\begin{tabular}{|c|c|c|c|c|c|c|c|c|c|}
\hline \multirow[t]{2}{*}{$\begin{array}{l}\text { Priming } \\
\text { uygulaması } \\
\text { Priming } \\
\text { treatment }\end{array}$} & \multicolumn{3}{|c|}{$\begin{array}{l}\text { Kök kuru ağırlığı } \\
\text { Root dry weight } \\
\quad\left(\mathrm{g} \text { bitki }{ }^{-1}\right)\end{array}$} & \multicolumn{3}{|c|}{$\begin{array}{c}\text { Toplam kuru madde miktarı } \\
\text { Total dry matter } \\
\left(\mathrm{g} \mathrm{bitki}^{-1}\right)\end{array}$} & \multicolumn{3}{|c|}{$\begin{array}{l}\text { Fide büyüme hızı } \\
\text { Seedling growth rate } \\
\left.\text { (mm gü }{ }^{-1}\right)\end{array}$} \\
\hline & SG-125 & Flash & Ort. & SG-125 & Flash & Ort. & SG-125 & Flash & Ort. \\
\hline $\mathrm{KNO}_{3}$ & 1.82 & 1.65 & $1.74 a^{* *}$ & $13.3 \mathrm{ab}^{* *}$ & $11.9 \mathrm{cde}$ & $12.6 a^{* *}$ & 10.82 & 8.88 & $9.85 a^{* *}$ \\
\hline Mannitol & 1.22 & 1.62 & $1.42 \mathrm{c}$ & $10.5 \mathrm{f}$ & $12.3 \mathrm{~b}-\mathrm{e}$ & $11.4 \mathrm{~b}$ & 10.68 & 8.93 & $9.81 \mathrm{a}$ \\
\hline KCL & 1.59 & 1.74 & $1.67 a b$ & 12.6 a-d & $12.9 \mathrm{abc}$ & $12.8 \mathrm{a}$ & 9.88 & 8.47 & 9.18 a \\
\hline Saf Su & 1.46 & 1.81 & $1.64 \mathrm{abc}$ & 11.3 ef & $13.6 \mathrm{ab}$ & $12.4 \mathrm{a}$ & 8.85 & 8.86 & $8.85 a$ \\
\hline
\end{tabular}

Aynı harf grubuna giren ortalamalar LSD testine göre *: \%5 önem seviyesine, ${ }^{* *}: \% 1$ önem seviyesine göre farksızdır.

The averages in the same letter group is no difference according to LSD test *: 5\% significance level, **: $1 \%$ significance level.

Çizelge 6'nın incelenmesinden, SG-125 pamuk çeşidinde en düşük toplam kuru madde miktarı $10.5 \mathrm{~g}$ ile PEG $10.6 \mathrm{~g}$ ile Mannitol uygulamasından, en yüksek ise $13.7 \mathrm{~g}$ ile Flash çeşidinin uygulamasız kontrol parselinden elde edildiği görülmektedir.
Flash pamuk çeşidinde ise en düşük toplam kuru madde miktarı $11.4 \mathrm{~g}$ ile $\mathrm{KCl}$ uygulamasından, en yüksek ise $13.7 \mathrm{~g}$ ile Kontrol uygulamasından saptanmıştır. íki çeşidin ortalama verilerine göre priming uygulamalarına bağı olarak saptanan en 
düşük toplam kuru madde miktarı $11 \mathrm{~g} \mathrm{bitki}^{-1}$ ile $\mathrm{KCl}$ uygulamasından, en yüksek ise $12.8 \mathrm{~g}$ bitki ${ }^{-1}$ ile $\mathrm{KCl}$ uygulamasından elde edilmiştir. Ortalama verilere göre Flash pamuk çeşidinde saptanan toplam kuru madde miktarı (12.6 $\mathrm{g}$ bitki ${ }^{-1}$ ), SG-125 pamuk çeşidinde saptanan toplam kuru madde miktarından (11.6 g bitki ${ }^{-1}$ ) daha yüksek bulunmuştur.

SG-125 pamuk çeşidinde en düşük bitki büyüme hızı $7.44 \mathrm{~mm}$ gün $^{-1}$ ile kontrol uygulamasından, en yüksek ise $10.82 \mathrm{~mm}$ gün $^{-1}$ ile $\mathrm{KNO}_{3}$ uygulamasından elde edilmiştir. Flash pamuk çeşidinde ise en düşük bitki büyüme hızı $7.31 \mathrm{~mm}$ gün ${ }^{-1}$ ile kontrol uygulamasından, en yüksek ise 8.93 $\mathrm{mm}$ gün $^{-1}$ ile mannitol uygulamasından saptanmıştır. İki çeşidin ortalama verilerine göre priming uygulamalarına bağlı olarak saptanan en düşük bitki büyüme hızı 7.37 $\mathrm{mm}$ gün ${ }^{-1}$ ile kontrol uygulamasından elde edilirken, en yüksek $9.85 \mathrm{~mm}$ gün ${ }^{-1}$ ile $\mathrm{KNO}_{3}$ uygulamasından elde edilmiştir. Ortalama verilere göre SG-125 pamuk çeşidinde saptanan bitki büyüme hızı (9.49 $\mathrm{mm} \mathrm{gün}^{-1}$ ), Flash pamuk çeşidinde saptanan bitki büyüme hızından $\left(8.50 \mathrm{~mm}\right.$ gün $\left.^{-1}\right)$ daha yüksek bulunmuştur.

Çizelge 5 ve $6^{\prime}$ daki sonuçlar birlikte değerlendirildiğinde, kök kuru ağırlığı, toplam kuru madde miktarı, kök uzunluğu ve sürgün kuru ağırlığı yönünden Flash çeşidinin SG-125 pamuk çeşidinden daha iyi durumda olduğu, fide büyüme hızının ise tam tersine SG-125 pamuk çeşidinde Flash çeşidinden daha yüksek olduğu görülmektedir. Kök kuru ağırlığı ve toplam kuru madde miktarı, kontrol ve $\mathrm{KNO}_{3}$ priming uygulamalarında diğer uygulamalardan daha yüksek saptanmıştır. Fide büyüme hızı yönünden tüm priming uygulamalarında kontrol uygulamasına kıyasla bir artış olduğu dikkati çekmektedir. Bitki boyu ve kök uzunluğu yönünden $\mathrm{KNO}_{3}$ uygulamasında diğer uygulamalara kıyasla artış kaydedilmiştir. Bu sonuçlar, pamukta fide gelişimi yönünden priming uygulamalarının, özellikle de $\mathrm{KNO}_{3}$ uygulamasının kontrol ve diğer uygulamalara kıyasla avantajlar sağlayabileceğini göstermektedir. Benzer konuda yürüttükleri araştırmalarda Ahmadvand ve ark., (2012) 6 $\mathrm{g} \mathrm{KNO}_{3} \mathrm{I}^{-1}$ konsantrasyonundaki solusyonda priming uygulaması yapılan pamuk tohumlarının, tuzluluk stresi koşullarında kontrole göre çimlenme parametrelerini olumlu etkilediğini ve kuru madde miktarını artırdığını; Shafiq ve ark., (2015), pamuk tohumlarına $\mathrm{KNO}_{3}$ priming uygulamasının klorofil a ve b oranını artırarak, biyokimyasal ve morfolojik modifikasyonlara neden olduğunu ve bu durumun pamuğun kuraklık stresi koşullarında daha iyi gelişim göstermesini sağladığını; Razaee ve ark. (2015), pamuk tohumlarına KNO3 priming uygulamasının tuzluluk stresinin olumsuz etkisini azalttığını; Santhy ve ark., (2014) pamuk tohumlarına hidrojen peroksit $\left(\mathrm{H}_{2} \mathrm{O}_{2}\right)$ priming uygulamasının, çimlenme esnasındaki su stresi koşullarında çimlenme oranını olumlu etkilediğini bildirmişlerdir. Pamuk tohumlarına farklı osmopriming uygulamalarından elde edilen bu bulgular, bizim elde ettiğimiz bulgularla benzerlik göstermektedir.

\section{Sonuçlar}

Pamukta SG-125 ve Flash pamuk çeşitlerinin tohumlarına farklı priming uygulamalarının laboratuvar ve saksı koşullarında çimlenme ve fide gelişimi ile ilgili bitkisel özelliklere etkisinin incelendiği bu çalışmada, hem laboratuvar hem de saksı koşullarında genel olarak Flash çeşidinin çimlenme özelliklerinin SG-125 çeşidine göre daha iyi olduğu gözlenmiştir. Bu bağlamda 
hem petri koşullarında hem de toprak koşullarında saptanan çimlenme hızı ve gücü ile sürme hızı ve gücü değerleri Flash çeşidinde, SG-125 çeşidine kıyasla önemli oranda daha yüksek saptanmıştır. Laboratuvar koşullarında yürütülen çimlendirme testi sonuçları özellikle çimlenme yüzdesi yönünden tohuma mannitol ve saf su uygulamalarının, uygulama yapılmayan tohumlara kıyasla avantaj sağladığını göstermektedir. Çim uzunluğu yönünden de çimlenme oranına benzer şekilde mannitol ve saf su uygulamaları artışa yol açmıştır. Pamuk tohumlarına $\mathrm{KNO} 3$ priming uygulamaları, saksı koşullarında özellikle bitki boyu, kök kuru ağırlı̆ı ve toplam kuru madde miktarı gibi özellikler üzerinde artırıcı etkide bulunmuştur. ilave olarak araştırma sonuçlarına göre tüm priming uygulamaları, kontrol uygulamasına göre fide büyüme hızında önemli artışa neden olmuştur. SG 125 ve Flash pamuk çeşitlerinin tohumlarına bazı priming uygulamalarının etkilerinin incelendiği bu araştırma sonuçları, mannitol, saf su ve $\mathrm{KNO}_{3}$ gibi uygulamaların çimlenme ve fide gelişimi yönünden kontrol uygulamasına kıyasla avantaj sağladığını göstermektedir.

\section{KAYNAKLAR}

Abandani, R.R., Ramezani, M., 2012. The Physiological Effects on Some Traits of Osmopriming Germination of Maize (Zea mays L.), Rice (Oryza sativa L.) and Cucumber (Cucumissativus L). International Journal of Agronomy, 4(2): 132-148.

Ahmadvand, G., Soleymani, F., Saadatian, B., Pouya, M., 2012. Effects of Seed Priming on Seed Germination and Seedling Emergence of Cotton Under Salinity Stress. World Applied Sciences Journal, 20 (11): 1453-1458.
Bagher, M., Asl, A., Taheri, G., 2012. Survey the Effect of Seed Priming on Germination and Physiological Indices of Cotton Khordad Cultivar. Annals of Biological Research, 3 (2): 1003-1009.

Bradford, K.J, 1986. Manipulation of Seed Water Relations Via Osmotic Priming to Improve Germination Under Stress Conditions. Horticultural Science, 21: 1105-1112.

Bradow, J.M., Bauer, P.J., 2010. Germination and Seedling Development. "Alınmıştır: Physiology of Cotton, J. McD. Stewart ve ark.2010"

Buxton, D.R., Sprenger, P.J., 1976. Genetic Variability for Cottonseed Germination at Favorable and Low Temperatures1. Crop Science, 16:243-246.

Caseiro, R., Bennett, M.A. and J. Marcos-Filho., 2004. Comparison of Three Priming Techniques for Onion Seed Lots Differing Initial Seed Quality. Seed Science and Technology, 32: 365-375.

Cheng, Z., Bradford, K.J., 1999. Hydrothermal Time Analysis of Tomato Seed Germination Responses to Priming Treatments. Journal of Experimental Botany, 33: 89-99.

De Villiers, A.J., Van Rooyen, M.V., Theron, G.K., Van De Venter, H.A., 1994. Germination of Three Namaqualand Pioneer Species, As Influenced By Salinity, Temperature and Light. Seed Science \& Technology, 22(3): 427-433.

Demir, I. and H. A. Van de Venter., 1999. The Effect of Priming Treatments on The Performance of Watermelon (Citrulus lanatus (Thunb.) Matsum. \& Nakai) Seeds Under Temperature Andosmotic Stress. Seed Science and Technology, 27(3): 871875.

Fujikura, Y., Kraak, H.L., Basra, A.S., Karssen, C.M., 1993. Seed and Technology. 21, 639-642.

Ghasemi-Golezani, K., Aliloo, A.A., Valizadeh, M., Moghaddam, M., 2008. Effects of Hydro and Osmo-Priming on Seed Germination and Field Emergence Lentil (Lens culinaris Medik.) Notulae Botanicae Horti Agrobotanici Cluj-Napoca, 36(1): 29-33.

Giri, G.S. and Schillinger, W.F., 2003. Seed Priming Winter Wheat for Germination, Emergence, and Yield. Crop Science, 43: 2135-2141.

Gummerson, R. J., 1986. The Effect of Constant Temperatures and Osmotic Potentials on 
the Germination of Sugar Beet. Journal of Experimental Botany, 37: 729-741.

Harris, D., Joshi, A., Khan, P.A., Gothkar, P., Sodhi, P.S., 1999. On Farm Seed Priming in SemiArid Agriculture Development and Evaluation in Maire, Rice And Chickpea in India Using Participatory Methods. Experimental Agriculture, 35: 15-29.

Harris, D., Rashid, A., Arif, M., Yunas, M., 2005. Alleviating Micronutrient Deficiencies in Alkaline Soils of The North-West Frontier Province of Pakistan: On-Farm Seed Priming With Zinc in Wheat and Chickpea. In: Andersen, Tuladhar P,Karki JK, Maskey KB. S.L. (Eds) Micronutrients in South and South East Asia, pp 143-151. Kathmandu: ICIMOD.

Hur, S.N., 1991. Effect of Osmoconditioning on The Productivity of Italian Ryegrass and Sorghum Under Suboptimal Conditions. Korean Journal of Animal Science, 33: 101105.

McDonalds, M. B., 2000. Seed Priming. In "Seed Technology and Its Biological Bases" (M. Black and J.D. Bewley, Eds.) pp. 287-325. Sheffield Academic Press Ltd. Sheffield.

Murungu, F.S. , Nyamugafata, P. , Chiduza, C., Clark, L.J., Whalley, W.R., 2005. Effects of Seed Priming and Water Potential on Germination of Cotton (Gossypium hirsutum L.) and Maize (Zea mays L.) in Laboratory Assays. South African Journal of Plant and Soil, 22(1): 64-70.

Nazir, M.S., Saad, A., Anjum, Y., Ahmad, W., 2014. Possibility of Seed Priming for Good Germination of Cotton Seed Under Salinity Stress, Journal of Biology, Agriculture and Healthcare, 4(8): 66-68.
Papastylianou, P.T., Karamanos, A.J., 2012. Effect of Osmopriming Treatments With Mannitol on Cottonseed Germination Performance Under Suboptimal Conditions. Seed Science and Technology, 40: 248-258.

Parera, A.C., Cantliffe, D.J., 1994. Pre-sowing Seed Priming. Horticultural Reviews, 16: 109148.

Rezaee, S., Moghaddam, M.R.R., Bazrgar, A.B., 2015. Cotton Seed Germination as Affected by Salinity and Priming. Indian Journal of Fundamental and Applied Life Sciences, 5(1): 312-318.

Shafiq, F., Batool, H., Raza, S.H., Hameed, M., 2015. Effect of Potassium Nitrate Seed Priming on Allometry of Drought-Stressed Cotton (Gossypium hirsutum L.), Journal of Crop Science and Biotechnology, 18(3): 195-204.

Shakila, A., Venkatesan, S., Babu, D., 2005. Influence of Osmopriming Agents on Seedling Performance in Chilli. Conservation \& Recycling, 18:147-155.

Taylor, A. G., Harman, G. E., 1990. Concepts and Technologies of Selected Seed Treatments. Annual Review of Phytopathology, 28: 321-339.

Thanos, C.A., Georghiou, K., and Passam, H.C., 1989. Osmoconditioning and Ageing of Pepper Seeds During Storage. Annals of Botany, 63: 65-69.

Toselli, M.E., Casenave, E.C., 2014. Is the Enhancement Produced By Priming in Cottonseeds Maintained During Storage?, Bragantia, Campinas, 73(4): 372-376. 